\title{
O EXAME NACIONAL DO ENSINO MÉDIO: O QUE REVELAM OS DADOS POR ÁREA DE CONHECIMENTO NUM PERÍODO DECENAL?
}

\author{
Daiane Gonçalves de Souza ${ }^{1}$, Aletheia Machado de Oliveira ${ }^{2}$, Tatiane Oliveira Santos Nascimento ${ }^{3}$ \\ ${ }^{1}$ Mestranda pelo Programa de Pós-Graduação em Educação da Universidade Estadual Paulista - UNESP, Faculdade de \\ Ciências e Tecnologia, Campus de Presidente Prudente, SP. ORCID iD: https://orcid.org/0000-0002-5151-9705. E-mail: \\ dai souza1992@hotmail.com.br, \\ ${ }^{2}$ Doutoranda pelo Programa de Pós-Graduação em Educação da Universidade Estadual Paulista - UNESP, Faculdade de \\ Ciências e Tecnologia, Campus de Presidente Prudente, SP ORCID iD: https://orcid.org/0000-0002-1058-0817. E-mail: \\ aletheiaoliveirajf@gmail.com. \\ ${ }^{3}$ Doutoranda pelo Programa de Pós-Graduação em Educação da Universidade Estadual Paulista - UNESP, Faculdade de \\ Ciências e Tecnologia, Campus de Presidente Prudente, SP. ORCID iD: https://orcid.org/0000-0001-5724-0732. E-mail: \\ tatiosn@hotmail.com
}

\section{RESUMO}

O presente trabalho teve como objetivo geral expor e analisar o contexto das médias gerais do Exame Nacional do Ensino Médio (ENEM) por área do conhecimento, por meio de dados coletados do site do Instituto Nacional de Estudos e Pesquisas Educacionais Anísio Teixeira (INEP), ao longo de 10 anos (20092018). Apresenta uma breve análise da trajetória do ensino médio no Brasil, bem como a idealização, a implementação e reformulação do ENEM e a forma como ocorre a avaliação deste exame. Partimos da abordagem quantitativa utilizando a estatística descritiva como método de análise dos dados coletados e realizamos uma pesquisa exploratória acerca do levantamento das seguintes áreas de conhecimento, a saber: Linguagens e Códigos e suas Tecnologias, Matemática e suas Tecnologias, Ciências Humanas e suas Tecnologias e Ciências da Natureza e suas Tecnologias. Para a coleta realizamos uma apuração crítica dos dados, utilizando-se da ferramenta tecnológica Microsoft Excel 2013, empregando algumas medidas descritivas através da média aritmética, variância e desvio padrão. Os dados revelam um discreto movimento com relação as notas médias em todas as áreas de conhecimento, com um notório distanciamento nas quatro áreas de conhecimentos entre as notas mínimas, médias e máximas, o que nos permite concluir que há um lineamento dos dados, isto é, pouco avanço na educação em termos quantitativos durante tal período.

Palavras-chave: Exame Nacional do Ensino Médio. Avaliação. Desempenho. Estatística Descritiva.

\section{THE NATIONAL HIGH SCHOOL EXAMINATION: WHAT DO THE KNOWLEDGE AREA DATA REVEAL IN A DECENAL PERIOD?}

\section{ABSTRACT}

The present paper had the general objective of exposing and analyzing the context of the general averages of the National High School Examination (ENEM) by area of knowledge, through data collected from the website of the National Institute of Educational Studies and Research Anísio Teixeira (INEP), over 10 years (2009-2018). It presents a brief analysis of the trajectory of secondary education in Brazil, as well as the idealization, implementation and reformulation of ENEM and the way in which the evaluation of this exam occurs. We started from the quantitative approach using descriptive statistics as a method of analysis of the collected data and carried out an exploratory research about the survey of the following areas of knowledge, namely: Languages and Codes and their Technologies, Mathematics and their Technologies, Human Sciences and their Technologies and Natural Sciences and its Technologies. For the collection, we performed a critical analysis of the data, using the technological tool Microsoft Excel 2013, employing some descriptive measures through the arithmetic mean, variance and standard deviation. The data reveal a discreet movement in relation to the average grades in all areas of knowledge, with a noticeable gap in the 
four areas of knowledge between the minimum, average and maximum grades, which allows us to conclude that there is a data alignment, ie, little progress in education in quantitative terms during such period.

Keywords: National High School Exam. Evaluation. Performance. Descriptive statistics.

\section{EL EXAMEN NACIONAL DE LA ESCUELA SECUNDARIA: ¿QUÉ REVELAN LOS DATOS DEL ÁREA DEL CONOCIMIENTO EN UN PERÍODO DECENAL?}

\section{RESUMEN}

El presente trabajo tuvo el objetivo general de exponer y analizar el contexto de los promedios generales del Examen Nacional de Escuelas Secundarias (ENEM) por área de conocimiento, a través de datos recopilados del sitio web del Instituto Nacional de Estudios e Investigación Educativa Anísio Teixeira (INEP), más de 10 años (2009-2018). Presenta un breve análisis de la trayectoria de la educación secundaria en Brasil, así como la idealización, implementación y reformulación de ENEM y la forma en que se realiza la evaluación de este examen. Partimos del enfoque cuantitativo utilizando estadística descriptiva como método de análisis de los datos recopilados y llevamos a cabo una investigación exploratoria sobre la encuesta de las siguientes áreas de conocimiento, a saber: Idiomas y códigos y sus tecnologías, Matemáticas y sus tecnologías, Ciencias humanas y sus tecnologías y Ciencias Naturales y sus Tecnologías. Para la recopilación, realizamos un análisis crítico de los datos, utilizando la herramienta tecnológica Microsoft Excel 2013, empleando algunas medidas descriptivas a través de la media aritmética, la varianza y la desviación estándar. Los datos revelan un movimiento discreto en relación con las calificaciones promedio en todas las áreas de conocimiento, con una brecha notable en las cuatro áreas de conocimiento entre las calificaciones mínima, promedio y máxima, lo que nos permite concluir que hay una alineación de datos, es decir , poco progreso en educación en términos cuantitativos durante dicho período.

Palabras-clave: Examen Nacional de Secundaria. Evaluación. Rendimiento Estadística Descriptiva.

\section{INTRODUÇÃO}

Presenciamos na vida cotidiana uma grande quantidade de dados que nos permite conceber o quanto a Estatística nos é útil. Através dos procedimentos de coleta, tratamento e análise quantitativa dos dados, podemos interpretar resultados e delinear conclusões.

A partir de um breve panorama histórico desse ramo da matemática aplicada, compreende-se que a Estatística se originou da necessidade de controle numérico através da catalogação simples de dados numéricos como: número de habitantes, de óbitos, estimativas de riqueza individual e social, entre outros. A partir do século $\mathrm{XVI}$, temos as primeiras análises sistemáticas, derivando as primeiras tábuas e tabelas. No século XVIII, os estudos dos fatos sociais foram assumindo formato científico com tabelas mais completas, o surgimento das primeiras representações gráficas e o cálculo das probabilidades. Godofredo Achenurall denominou a nova ciência de Estatística (CRESPO, 2009, p. 02).
Atualmente, percebemos a empregabilidade da Estatística em diversas áreas do conhecimento. Em dados educacionais, observamos que a aplicação de técnicas e procedimentos de análises estatísticas estão voltadas para análise e interpretação de dados referentes à evasão escolar, frequência, alfabetização, matrícula, repetência dos alunos, desempenho dos alunos, distorção série/idade, entre outros. No Exame Nacional do Ensino Médio (ENEM), constatamos essa empregabilidade das informações estatísticas visando o desenvolvimento de estudos e indicadores educacionais para interpretar a qualidade do ensino no nível médio.

Sabemos que o ENEM, foi concebido para avaliar as habilidades e competências ${ }^{1}$ dos alunos, além de oportunizar o acesso a vagas oferecidas pelas Instituições de Ensino Superior nos mais variados locais do nosso país. Em artigo

\footnotetext{
1 Maiores informações referentes às habilidades e competências que fundamentam o ENEM através das matrizes de referências por áreas de conhecimento, encontram-se nas páginas 18-30. (BRASIL, 2012).
} 
de opinião intitulado Enem: uma avaliação inovadora, Castro (1999, p. 01) destaca que esse instrumento de avaliação está ajustado com a Lei de Diretrizes e Bases da Educação Nacional, "[...] que incentiva as avaliações educacionais, acaba com a obrigatoriedade do vestibular e propõe a articulação estreita entre o ensino médio e as universidades".

A referida autora destaca, também, que essa avaliação inovadora incentiva as escolas a desenvolver habilidades e competências para que os alunos possam aplicar as informações em contextos apropriados, valendo-se de tudo o que foi aprendido para ser empregado no contexto em que vive de forma relevantes.

Atendo-se as matrizes de referência do ENEM, estas apresentam dois vetores: os Eixos Cognitivos (Habilidades) e as Competências de área. Segundo Brasil (2012, p. 17), o primeiro vetor "[...] corresponde a domínios da estrutura mental e funciona de maneira orgânica e integrada às Competências de área" e o segundo vetor " [...] organiza as Habilidades à luz das especificidades curriculares em cada uma das Áreas do Conhecimento".

Considerando a discussão que envolve ENEM torna-se válido refletir: o que revelam as médias gerais do ENEM por área do conhecimento? Os resultados apontam melhorias da qualidade de ensino por área do conhecimento? Há progresso ou não?

Com base nessas questões norteadoras se originou o presente trabalho, cujo objetivo geral deu-se em expor e analisar o contexto das médias gerais do ENEM por área do conhecimento, através de dados coletados do site do Instituto Nacional de Estudos e Pesquisas Educacionais Anísio Teixeira (INEP), ao longo de 10 anos (2009-2018), considerando o cenário atual da educação básica brasileira, em relação ao ensino médio.

A organização deste trabalho apresenta, logo após a introdução, uma breve análise da trajetória do ensino médio no Brasil, considerado a última etapa da educação básica e que antecede a admissão ao ensino superior, bem como a análise de leis e reformas referentes a esta modalidade de ensino. Em seguida, discorremos sobre a idealização, a implementação e reformulação do Exame Nacional do Médio (ENEM). Logo após, relatamos a maneira como se constituí a avaliação deste exame. Na metodologia, apresentamos as fases de aplicação da estatística descritiva para expor os dados obtidos a partir de um levantamento das médias gerais nacionais do exame, por área de conhecimento, ao longo de 10 anos. Em resultados e discussões, refletimos sobre o quanto avançamos ou não nas áreas do conhecimento e o que essas médias representam para a educação brasileira. Por fim, realizamos uma reflexão sobre o que tal estudo nos demonstrou perante todo o contexto educacional do ensino médio.

\section{TRAJETÓRIA HISTÓRICA DO ENSINO MÉDIO NO BRASIL}

No contexto brasileiro, o Ensino Médio é considerado a última etapa da educação básica, e antecede a admissão ao ensino superior. Brzezinski et al. (2001) pontuam que historicamente esta etapa busca uma identidade unificadora, a fim de vencer a dualidade entre o ensino preparatório para a universidade e o atendimento ao mercado de trabalho.

Em uma breve análise da trajetória do Ensino Médio no Brasil, denominação atual, observamos que esta modalidade de ensino recebia o nome de ensino secundário. Romanelli (2010) destaca que até 1930, o ensino secundário visava a preparação para exames de admissão ao ensino superior. Eram cursos preparatórios, de caráter propedêutico, classista e acadêmico. Predominava o sistema dualista de ensino, ou seja, de um lado o ensino primário destinado à população de baixa renda e vinculado às escolas profissionais e de outro o ensino secundário destinado à população de alta renda e articulado ao ensino superior. $O$ ensino secundário apresentava-se no formato de cursos preparatórios e não tinha organização curricular desse sistema educativo.

Após 1930, Romanelli (2010) pontua que com a Reforma Francisco Campos efetivada através do decreto-lei no 19.890 , de 18 de abril de 1931, que dispõe sobre a organização do ensino secundário e do decreto-lei no 21.241 , de 14 de abril de 1932, que consolida as disposições sobre a organização do ensino secundário, estabeleceu-se a organicidade desta etapa, a nível legal, por meio de várias medidas, como implantação do currículo enciclopédico, frequência obrigatória, divisão em dois ciclos: o primeiro, de 05 anos, e denominado ciclo fundamental com formação geral e o segundo, de 02 anos, e denominado ciclo complementar era propedêutico com três opções: curso de Direito, cursos de Medicina, Odontologia e Farmácia e 
cursos de Engenharia e Arquitetura e um rigoroso sistema de avaliação para os discentes.

Em 1942, a autora destaca a chamada Lei Orgânica do Ensino Secundário pelo Decreto-lei no 4.244, de 09 de abril de 1942, conhecida como Reforma Capanema. Este ensino, segundo Romanelli (2010, p. 161) deveria “[...] proporcionar cultura geral e humanística; alimentar uma ideologia política definida em termos de patriotismo e nacionalismo de caráter fascista; proporcionar condições para o ingresso no curso superior e possibilitar a formação de lideranças".

A respeito do caráter educacional em nada mudou comparando com a Reforma Francisco Campos ao acentuar o ensino propedêutico, a preparação para ingresso no ensino superior, a rigidez no sistema avaliativo, a seletividade e destinado à parcela da população de alta renda. O único ponto que difere da Reforma Francisco Campos refere-se à reestruturação do currículo: o primeiro ciclo que se chamava ginasial com 04 séries e o segundo ciclo subdividido em curso clássico e curso científico, ambos com 03 séries. (ROMANELLI, 2010).

Em 1961, temos que destacar a lei no 4.024, de 20 de dezembro 1961, que fixa das Diretrizes e Bases da Educação Nacional, como o primeiro documento que regulamenta o sistema de ensino público e privado no Brasil. Na referida lei, o Ensino Médio é tratado nos arts. 33 a 43, título VII, capítulo I. Com a sua aprovação, a rigidez referente à organização do ensino secundário é rompida. Flexibilidade curricular, procedimentos de avaliação, autonomia para cada unidade de ensino organizar-se na constituição dos cursos e regime administrativo, disciplinar e didático através de regimentos ou estatutos são alguns aspectos a serem destacados (BRASIL, 1961).

Com a lei no 5.692 de 11 de agosto de 1971 , temos a criação da escola de 1 ㅇ e $2^{\circ}$ g graus. Atendo-se ao ensino de 20 grau, no capítulo III, art. 21, 22 e 23 , sua organização será de três a quatro séries anuais, com carga horária de 2.200 ou 2.900 horas para a formação do adolescente. O currículo desta modalidade será composto por educação geral e formação especial, visando a habilitação profissional. (BRASIL, 1971).

No contexto atual, a lei no 9.394 de 20 de dezembro de 1996, seção IV, art. 35, afirma que essa etapa da educação, tem duração de três anos e tem como objetivos principais:
[...] a consolidação e o aprofundamento dos conhecimentos adquiridos no ensino fundamental, possibilitando o prosseguimento de estudos; a preparação básica para o trabalho e a cidadania do educando, para continuar aprendendo, de modo a ser capaz de se adaptar com flexibilidade a novas condições de ocupação ou aperfeiçoamento

posteriores; 0 aprimoramento do educando como pessoa humana, incluindo a formação ética e o desenvolvimento da autonomia intelectual e do pensamento crítico; a compreensão dos fundamentos científicotecnológicos dos processos produtivos, relacionando a teoria com a prática, no ensino de cada disciplina (BRASIL, 1996, art. 35).

Com a reforma do Ensino Médio, ocorrida através da lei no 13.415, de fevereiro de 2017 (BRASIL, 2017), algumas mudanças foram realizadas na vigente Lei de Diretrizes e Bases da Educação. Conforme tal alteração no art. 36, "o currículo do ensino médio será composto pela Base Nacional Comum Curricular e por itinerários formativos[...]", os quais serão "[...] organizados por meio da oferta de diferentes arranjos curriculares[...]", isto de acordo com "[...] o contexto local e a possibilidade dos sistemas de ensino[...]" (BRASIL, 1996).

Destacamos que essas mudanças ocorridas no sistema educacional ao longo de todo processo possibilitaram diferenciais no Ensino Médio como a ampliação progressiva da carga horária, atualização e flexibilização curricular a partir da Base Nacional Comum Curricular (BNCC), abordagens pedagógicas mais práticas e interativas para que o aluno possa articular teoria e prática, estímulo à reflexão crítica, problematização e avaliação de caráter diagnóstico e formativo. 


\subsection{ENEM: origens e reformulações}

Instituído em 28 de maio de 1998 através da portaria no 438, o ENEM foi idealizado para avaliar as habilidades e competências esperadas pelos alunos ao final da educação básica. 0 exame foi realizado pela primeira vez no dia 30 de agosto de 1998, pelo INEP. Além de auxiliar o acesso à educação superior e aos programas governamentais de financiamento e apoio estudantil, os resultados possibilitam 0 desenvolvimento de estudo e indicadores sobre a educação brasileira (BRASIL, 1998).

Desde sua implementação até o ano de 2008, esta avaliação era constituída por um caderno de provas com 63 questões interdisciplinares, a fim de avaliar as capacidades e competências dos estudantes adquiridas durante toda a educação básica. Em 2004, foi fundado o Programa Universidade para todos (ProUni), criado pelo Ministério da Educação (MEC), que estabeleceu a disponibilidade de bolsas de estudos integrais, e bolsas de estudos parciais com cinquenta por cento nas universidades privadas de ensino superior, com ou sem fins lucrativos, através dos resultados do ENEM.

Posteriormente, em 2009, houve a necessidade de uma reformulação das Matrizes de Referência para o ENEM, tendo como guia as Matrizes de Referência do Exame Nacional para Certificação de Competências de Jovens e Adultos (Encceja) por meio de quatro áreas de conhecimento $^{2}$. Essa matriz, publicada pelo INEP (BRASIL, 2012), abrange alguns eixos cognitivos comuns a todas as áreas de conhecimentos, são eles:

I. Dominar linguagens (DL): dominar a norma culta da Língua Portuguesa e fazer uso das linguagens matemática, artística e científica e das línguas espanhola e inglesa.

II. Compreender fenômenos (CF): construir e aplicar conceitos das várias áreas do conhecimento para compreensão de fenômenos naturais, de processos históricogeográficos, da produção

\footnotetext{
${ }^{2}$ A partir de 2016, o ENEM não certifica mais em nível médio.
}

\begin{tabular}{|c|}
\hline 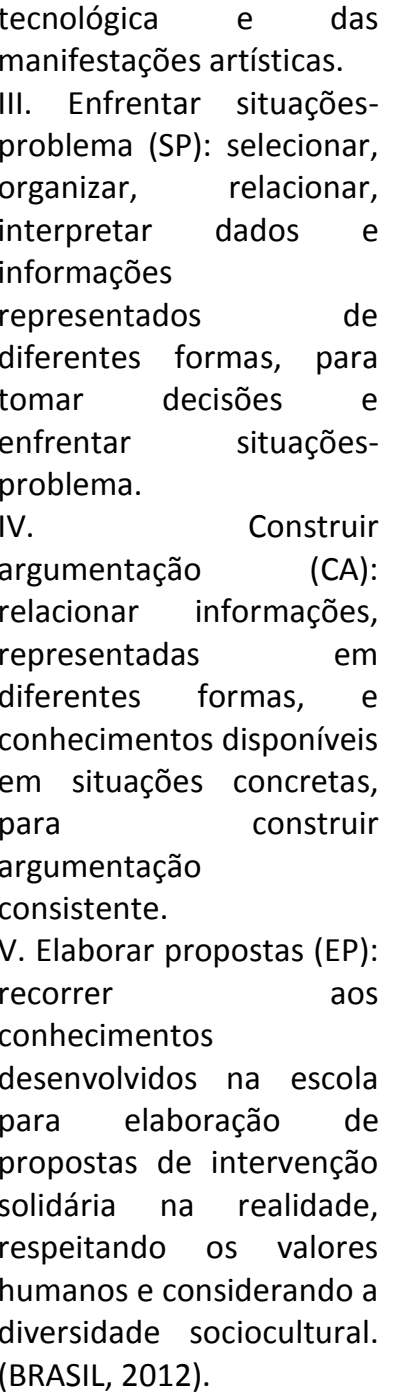 \\
\hline
\end{tabular}

Realizado anualmente e aplicado em dois domingos consecutivos, apresenta formato com 180 questões referentes às quatro áreas específicas do conhecimento, além da redação. A instrumentalização e planejamento é de competência do INEP, autarquia federal vinculada ao Ministério da Educação (MEC). No primeiro dia, os candidatos realizam as provas de ciências humanas e tecnologias; e ciências naturais e suas tecnologias; já no segundo dia, são avaliadas as áreas de Linguagens, Códigos e suas Tecnologias; Matemática e suas Tecnologias e a redação. No que se refere à redação, as competências averiguam diversos dados de percepção e de produção do texto, o tipo textual é dissertativoargumentativo, e pode obter de sete até 30 linhas. Com base no tema determinado na redação, os participantes devem atender ao referido tipo de texto, além de desenvolver ao longo de seu texto, uma intervenção respeitando os direitos dos indivíduos, bem como apresentar sua opinião referente ao assunto abordado. 
Também, é considerado como forma de avaliação, um questionário socioeconômico, 0 qual é preenchido pelos participantes no momento da inscrição. O questionário é aplicado desde a primeira edição do ENEM, o mesmo permite interpretar informações relevantes a respeito da vida dos estudantes, elencando dados socioeconômicos e profissionais das famílias dos participantes, trajetória escolar, perspectivas do futuro, entre outros aspectos importantes.

Quadro 01. Diferenças entre o antigo e o novo ENEM

\begin{tabular}{|l|l|}
\hline \multicolumn{1}{|c|}{ De 1998 até 2008} & \multicolumn{1}{c|}{ De 2009 até os dias atuais } \\
\hline $\begin{array}{l}\text { Formato: prova única com } 63 \text { questões e e } \\
\text { uma redação. }\end{array}$ & $\begin{array}{l}\text { Formato: 04 provas com 45 questões e uma } \\
\text { redação. }\end{array}$ \\
\hline Duração: 05 horas e aplicada em um dia. & $\begin{array}{l}\text { Duração: 04 horas e meia no primeiro dia e } \\
\text { 05 horas e meia no segundo dia, totalizando } \\
\text { dois dias. }\end{array}$ \\
\hline $\begin{array}{l}\text { Disciplinas requeridas: Português, Geografia, } \\
\text { História, Biologia, Matemática, Física e e } \\
\text { euímica e redação. }\end{array}$ & $\begin{array}{l}\text { Disciplinas requeridas: por áreas do } \\
\text { (Matemática, Linguagens e Códigos, Ciências } \\
\text { Humanas e Ciências da Natureza) e redação. }\end{array}$ \\
\hline $\begin{array}{l}\text { Provas: estruturadas a partir de uma matriz } \\
\text { de 21 habilidades. }\end{array}$ & $\begin{array}{l}\text { Provas: estruturadas a partir de 04 matrizes } \\
\text { de referência para cada área do } \\
\text { conhecimento. }\end{array}$ \\
\hline $\begin{array}{l}\text { Resultados das notas: utilizadas como } \\
\text { complemento para ingresso nas IES. }\end{array}$ & $\begin{array}{l}\text { Resultados das notas: utilizadas de forma } \\
\text { integral para ingresso nas IES. }\end{array}$ \\
\hline
\end{tabular}

Fonte: Autoras (2019)

Nota: Elaborado com dados do INEP (BRASIL, 2019)

Sendo assim, foi a partir da reformulação que a avaliação constitui-se como um dos meios para acesso as Universidade Federais, Estaduais e Particulares do Brasil. Além de tais eixos cognitivos, as Matrizes de Referência do ENEM, foram organizadas por competência de cada área. O novo modelo do exame dispõe de quatro áreas do conhecimento, constituídas pela área de Ciências Humanas e suas Tecnologias, a qual corresponde à disciplina de história, geografia, filosofia e sociologia; pela área de Ciências da Natureza e suas Tecnologias, que se refere química, física e biologia; área de Matemática e suas Tecnologias, que trata da disciplina de matemática; e a área de Linguagens, Códigos e suas Tecnologias e redação, que diz respeito às disciplinas de língua portuguesa, literatura, língua estrangeira (inglês ou espanhol), artes, educação física e tecnologias da informação e comunicação.

Comemorando 20 anos no ano de 2018, o ENEM foi inspirado na primeira reunião de Jomtien, Tailândia, de educação para todos. Apresenta uma matriz de competências que envolve aspectos práticos, culturais, éticos para cidadania, quais sejam: dominar linguagens, compreender fenômenos, enfrentar situaçõesproblema, construir argumentações e elaborar propostas que estão associadas a vinte e uma habilidades com vocação em contexto da realidade atuante do candidato.

Sakalauskas e Trevisan (2017) realizaram uma pesquisa com um grupo de pessoas que prestaram o exame nos anos de 2013 e 2014 com o objetivo de identificar o perfil desses candidatos, os motivos da escolha e conhecer os caminhos que pretendiam trilhar após a 
conclusão de Ensino Médio. As conclusões do estudo revelaram que essa forma de certificação é um caminho importante para o ingresso em Instituições de Ensino Superior (IES), sejam federais, estaduais ou particulares.

Assim, o ENEM consiste num exame que visa avaliar competências e habilidades de cada indivíduo de maneira particular, de acordo com seu desenvolvimento durante a educação básica, além de ser usado por milhares de estudantes do país para tentar o ingresso em Instituições de Ensino Superior.

As questões tratadas no exame apresentam situações-problemas. Os resultados do ENEM são utilizados tendo em vista funções, desde para o mercado de trabalho, requisito para o ingresso ao ensino superior, como também para o provimento de bolsas de estudos, acesso às universidades particulares, públicas, obtenção da certificação do ENEM, entre outros. Além disso, essa avaliação possibilita uma autoavaliação por parte dos participantes, além de permitir a reflexão por parte dos pais, professores, responsáveis pelas unidades escolares, o que contribui para reflexões sobre as práticas de educação, a fim de visar pela melhoria da qualidade educacional, tendo em vista que "[...] a qualidade não é definida pelo resultado em uma prova, mas, antes, é entendida como um direito social e político de todos" (BRASIL, 2013, p. 109).

\subsection{Modelo de avaliação do ENEM}

As notas do ENEM são classificadas numa escala de 0 a 1000, mas é importante destacar que as notas não são mais calculadas pelo número de acertos, e nem pelo nível de dificuldade das questões acertadas, para essa aferição. O INEP adotou em 2009 a Teoria da Resposta ao Item (TRI) ${ }^{3}$, com o propósito de dar coerência aos acertos, como também não identificar se um aluno participante acertou a questão ao acaso, ou não. Diferentemente da Teoria Clássica dos Testes (TCT), empregada em anos anteriores a 2009, considerando apenas o total de acertos, a Teoria de Resposta ao Item julga o grau de dificuldade das questões e a coerência pedagógica dos acertos, além de verificar o nível de dificuldade de cada item através de fórmulas estatísticas.

\footnotetext{
${ }^{3}$ Para maiores informações sobre a Teoria da Resposta ao Item clicar no link "Saiba mais" que encontrar-se ao final da página http://portal.inep.gov.br/artigo//asset_publisher/B4AQV9zFY7Bv/c ontent/o-que-e-tri/21206?rel=outbound
}

As questões do ENEM são classificadas com pesos diferentes, considerando que na prova tem questões: fáceis, medianas e difíceis. Isso implica que pessoas que acertem o mesmo número de questões na mesma edição do ENEM não terão a mesma nota. Por exemplo, se a questão mais fácil da prova tem proficiência 370 , esta será a menor nota, como não existem itens que avaliem proficiências menores que 370 , a única inferência possível é de que o aluno tem no máximo proficiência 370 , mas é possível que tenha notas abaixo desse valor. Se um aluno que obteve nota 960 , pode ter proficiência maior, mas a escala TRI não permite mensurar.

Diante disso, a TRI considera relevante acertar questões fáceis, médias e, sendo possível, algumas questões difíceis. Por meio desse padrão, a TRI declara que ocorreu coerência pedagógica, por isso, quando acontece de igual maneira descrita acima, aumenta-se a pontuação do participante, caso contrário, quando não há coerência pedagógica, então, a nota do estudante é reduzida. Assim, pode acontecer que estudantes com acertos iguais, tenham notas diferentes, ou mesmo, um estudante pode ter a quantidade de acertos menor, mas sua nota ser maior em relação a outras pessoas que acertaram uma quantidade maior de questões na mesma prova. De acordo com a TRI, todos os acertos são válidos, e posteriormente é calculado a nota do aluno, por isso não há pontuação específica para cada questão.

Em relação à redação, sabe-se que tal avaliação requer a produção de um texto do tipo dissertativo-descritivo com tema de esfera política, científica, cultural ou social. A avaliação é realizada com base em cinco competências, são elas: apresentar domínio da língua portuguesa; compreender o tema proposto; organizar as ideias, informações e opiniões; mostrar conhecimento a respeito da organização do texto argumentativo e produzir uma proposta de intervenção ao tema acometido. A prova de redação é avaliada por dois professores, em que cada um deles, concerne uma nota entre 0 a 200 para cada competência referida. A nota dá-se por meio da média aritmética das notas dadas pelos dois professores. A nota atribuída pode ser de 0 a 1.000 pontos. Caso ocorra de uma ou mais competências obterem diferença maior que 80 pontos, é necessário um terceiro avaliador para atribuir a nota de determinada competência. Um terceiro avaliador também é solicitado se a diferença da pontuação total das cinco 
competências for maior que 100 pontos, o que neste caso, a nota final será a média das duas notas com maior proximidade.

\section{METODOLOGIA}

Neste estudo optamos pela abordagem quantitativa que se caracteriza, segundo Richardson et. al (2012, p. 70), "[...] pelo emprego da quantidade tanto nas modalidades de coletas de informações, quanto no tratamento delas por meio de técnicas estatísticas[...]", como por exemplo média, desvio-padrão, variância, coeficiente de correlação linear, regressão, indicadores, entre outros.

Por meio dessa abordagem, priorizamos realizar um levantamento dessas médias a partir de 2009 em função da reformulação das matrizes de referência com base nas Matrizes de Referência do Exame Nacional para Certificação de Competências de Jovens e Adultos (Encceja).

Para isso, propomos apresentar um levantamento das médias nacionais do ENEM, por área de conhecimento, a saber:

Quadro 02. Área de conhecimento e disciplinas associadas

\begin{tabular}{|l|l|}
\hline \multicolumn{1}{|c|}{ Área de conhecimento } & \multicolumn{1}{|c|}{ Componentes Curriculares } \\
\hline Linguagens, Códigos e suas Tecnologias & $\begin{array}{l}\text { Língua Portuguesa, Literatura, Língua Estrangeira } \\
\text { (Inglês ou Espanhol), Artes, Educação Física e } \\
\text { Tecnologias da Informação e Comunicação. }\end{array}$ \\
\hline Matemática e suas Tecnologias & Álgebra e Geometria \\
\hline Ciências Humanas e suas Tecnologias & História, Geografia, Filosofia e Sociologia \\
\hline Ciências da Natureza e suas tecnologias & Química, Física e Biologia \\
\hline \multicolumn{2}{|l}{ Redação } \\
\hline
\end{tabular}

Fonte: Autoras (2019)

Nota: Elaborado com dados de QEdu (2019)

Para a coleta, crítica, apuração, exposição e análise dos dados utilizamos a estatística descritiva como método de análise.

A coleta de dados foi indireta - realizada sobre elementos informativos de registro das médias gerais por área de conhecimento através do site do INEP - e periódica num intervalo constante entre 2009 e 2018.

A apuração dos dados foi eletrônica com o uso do software Microsoft Excel 2013 para o sistema operacional Windows. Para isso, aplicamos algumas medidas descritivas visando obter informações a respeito do comportamento dos dados apresentados na Tabela 01, a saber: média aritmética, variância e desvio padrão.
Para a exposição dos dados construímos tabelas e gráficos utilizando o mesmo software descrito anteriormente, a partir dos dados obtidos através das medidas estatísticas.

\section{RESULTADOS E DISCUSSÕES}

Para realizar a análise dos dados, expomos a tabela abaixo com informações filtradas no site no INEP, que demonstram as respectivas notas mínimas, médias e máximas por área de conhecimento ao longo do período decenal. 
Tabela 01. Média Geral, Variância e Desvio Padrão por área de conhecimentos

\begin{tabular}{|c|c|c|c|c|c|c|c|c|c|c|c|c|}
\hline \multirow{2}{*}{ ANO } & \multicolumn{3}{|c|}{$\begin{array}{l}\text { Linguagens, Códigos e } \\
\text { suas Tecnologia }\end{array}$} & \multicolumn{3}{|c|}{$\begin{array}{c}\text { Matemática e suas } \\
\text { Tecnologias }\end{array}$} & \multicolumn{3}{|c|}{$\begin{array}{l}\text { Ciências Humanas e } \\
\text { suas Tecnologias }\end{array}$} & \multicolumn{3}{|c|}{$\begin{array}{c}\text { Ciências da Natureza e } \\
\text { suas tecnologias }\end{array}$} \\
\hline & $\begin{array}{c}\text { Nota } \\
\text { mínima }\end{array}$ & $\begin{array}{c}\text { Nota } \\
\text { média }\end{array}$ & $\begin{array}{c}\text { Nota } \\
\text { máxima }\end{array}$ & $\begin{array}{c}\text { Nota } \\
\text { mínima }\end{array}$ & $\begin{array}{c}\text { Nota } \\
\text { média }\end{array}$ & $\begin{array}{c}\text { Nota } \\
\text { máxima }\end{array}$ & $\begin{array}{c}\text { Nota } \\
\text { mínima }\end{array}$ & $\begin{array}{l}\text { Nota } \\
\text { média }\end{array}$ & $\begin{array}{c}\text { Nota } \\
\text { máxima }\end{array}$ & $\begin{array}{c}\text { Nota } \\
\text { mínima }\end{array}$ & $\begin{array}{l}\text { Nota } \\
\text { média }\end{array}$ & $\begin{array}{c}\text { Nota } \\
\text { máxima }\end{array}$ \\
\hline 2009 & 224,3 & 529,9 & 835,6 & 345,9 & 665,5 & 985,1 & 300 & 593,5 & 887 & 263,3 & 583,2 & 903,2 \\
\hline 2010 & 254 & 509,8 & 801,1 & 313,4 & 505,2 & 973,2 & 265,1 & 548 & 883,7 & 297,3 & 487,3 & 844,7 \\
\hline 2011 & 301,2 & 520,9 & 795,5 & 321,6 & 517,2 & 953 & 252,8 & 478 & 793,1 & 265 & 466,5 & 867,2 \\
\hline 2012 & 295,2 & 494,2 & 817,9 & 277,2 & 509 & 955,2 & 295,6 & 523,7 & 874,9 & 303,7 & 473,2 & 864,9 \\
\hline 2013 & 261,3 & 502,5 & 813,3 & 322,4 & 544,4 & 971,5 & 299,5 & 533,1 & 888,7 & 311,5 & 486,2 & 901,3 \\
\hline 2014 & 306,2 & 507,9 & 814,2 & 318,5 & 473,5 & 973,6 & 324,8 & 546,5 & 862,1 & 330,6 & 482,2 & 876,4 \\
\hline 2015 & 302,6 & 505,3 & 825,8 & 280,2 & 467,9 & 1008,3 & 314,3 & 558,1 & 850,6 & 334,3 & 478,8 & 875,2 \\
\hline 2016 & 287,5 & 520,5 & 846,4 & 309,7 & 489,5 & 991,5 & 317,4 & 533,5 & 859,1 & 316,5 & 477,1 & 871,3 \\
\hline 2017 & 299,6 & 510,2 & 788,8 & 310,4 & 518,5 & 993,9 & 307,7 & 519,3 & 868,3 & 298 & 510,6 & 885,6 \\
\hline 2018 & 318,8 & 526,9 & 816,9 & 360 & 535,5 & 996,1 & 387,2 & 569,2 & 850,4 & 362,5 & 493,8 & 869,6 \\
\hline Média Aritmética & 285,07 & 512,81 & 815,55 & 315,93 & 522,62 & 980,14 & 306,44 & 540,29 & 861,79 & 308,27 & 493,89 & 875,94 \\
\hline Variância & 854,96 & 129,35 & 311,04 & 641,49 & 3121,58 & 323,87 & 1315,13 & 975,11 & 781,62 & 926,28 & 1131,40 & 301,80 \\
\hline Desvio Padrão & 29,24 & 11,37 & 17,64 & 25,33 & 55,87 & 18,00 & 36,26 & 31,23 & 27,96 & 30,43 & 33,64 & 17,37 \\
\hline
\end{tabular}

Fonte: Autoras (2019)

Nota: Elaborado a partir de dados do INEP (BRASIL, 2019)

Para a apuração dos dados referentes as notas mínimas, máximas e médias por área de conhecimento, utilizamos a medida de posição média aritmética e as medidas de dispersão variância e desvio padrão.

Para os autores Crespo (2009) e Martins e Domingues (2017), a média é a mais comum das medidas de posição empregadas em um grande número de situações práticas em que somamos os valores da amostra (ou da população) e dividimos pelo número de observações da amostra (ou da população).

A partir do conceito dos autores sobre média aritmética, podemos verificar que as notas mínimas independentes da área de conhecimento/conteúdo encontram-se muito próximas umas das outras, isto é, num intervalo [285;309]. O mesmo vale para as notas médias [493;541] e as notas máximas [815;981] , de onde aferimos que não há uma discrepância tão considerável entre o domínio de conhecimento/conteúdo por parte dos alunos do Ensino Médio participantes do exame. Percebe-se que a "falha" para consideradas médias tão próximas permeia no âmbito de todas as disciplinas associadas da prova.

Em variância, Crespo (2009, p. 105) destaca que é uma medida bem importante na inferência estatística e "[...] baseia-se nos desvios em torno da média aritmética [...]", indicando o quão longe em geral os seus valores se encontram do valor esperado. A variância mede o quanto os dados estão distanciados no tocante à média, ou seja, quanto menor é a variância, mais próximos os valores estão da média aritmética e quanto maior ela é, mais os valores estão distantes.

Temos que em Linguagens, Códigos e suas Tecnologias a nota mínima da variância está acima da média aritmética e as notas média e máxima estão abaixo da variância. Em Matemática e suas Tecnologias, a variância da nota mínima e média estão acima e a máxima apresenta-se abaixo da média aritmética. Já em Ciências Humanas e suas Tecnologias todas as notas da variância estão acima da média e, por fim, em Ciências da Natureza e suas Tecnologias nota mínima e média da variância estão acima e nota máxima abaixo da média aritmética.

Já a medida de dispersão desvio padrão é considerada uma das mais importantes, pois mede o quão diferente os valores de um conjunto de dados (amostra/população) se diferem entre si. Crespo (2009, p. 74) define-a como "[...] a diferença entre cada elemento de um conjunto de valores e a média aritmética", ou seja, indica a dispersão média absoluta dos dados em torno da média".

Vemos pelos dados do desvio padrão referentes a nota média da tabela 1 , apresentada acima, que há uma considerável dispersão dos dados, tanto na nota mínima quanto a nota média e máxima. Podemos constatar tal inferência no gráfico abaixo. 
Gráfico 1. Desvio Padrão das notas médias por área de conhecimento

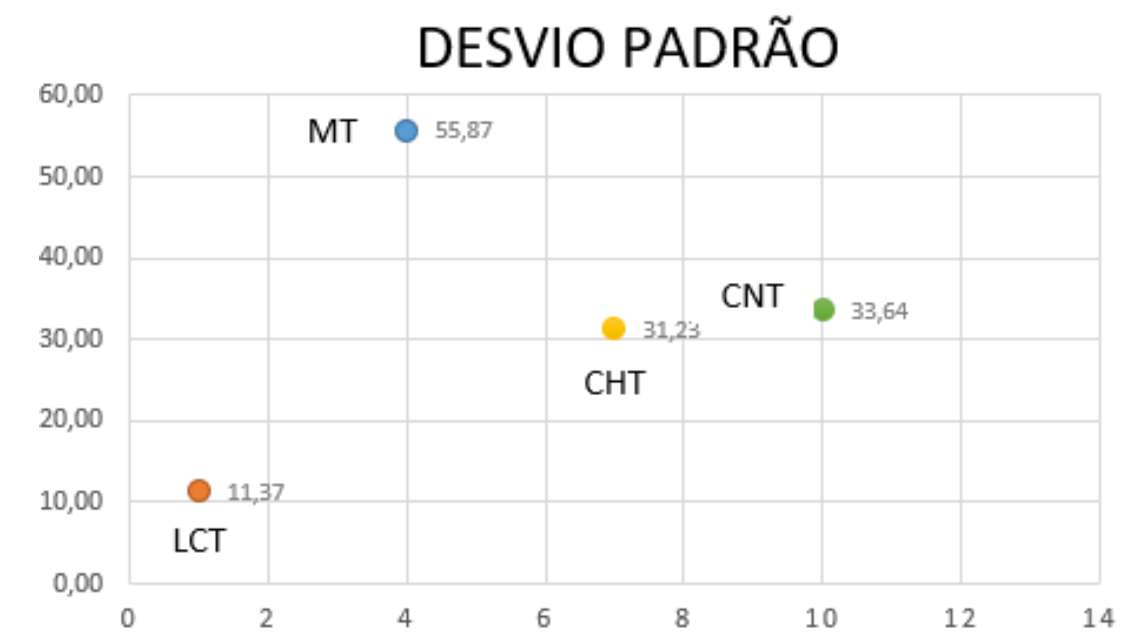

Fonte: Autoras (2019)

Para facilitar a análise dos dados, também, expomos os gráficos por área de conhecimento, apresentando acompanhamento das médias gerais para cada área.

Gráfico 2. Notas mínimas, máximas e média de Linguagens, Códigos e suas Tecnologias

\section{LINGUAGENS, CÓDIGOS E SUAS TECNOLOGIAS}

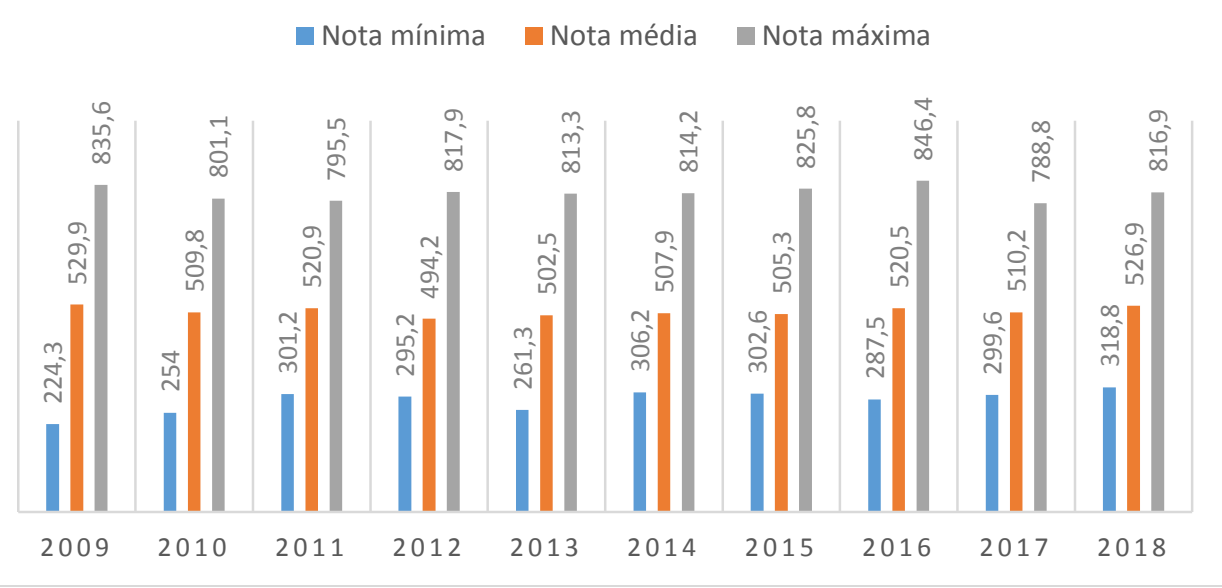

Fonte: Autoras (2019)

Observamos que as médias gerais de Linguagens, Códigos e suas Tecnologias estão muito próximas, variando nesses dez anos num intervalo de [494;-529,9], representando a menor e a maior nota respectivamente em 2012 e 2009, ano quando curiosamente foi implantado o novo perfil do ENEM. Esta análise demonstra que não houve uma grande discordância em relação as notas desse campo de conhecimento. Por Linguagens, Códigos e suas tecnologias abranger disciplinas tão essenciais para a compreensão das demais áreas analisadas e conter objetos de conhecimento como estudo de textos (literários, argumentativos, gêneros digitais) e estudo dos aspectos linguísticos presentes nesses textos (BRASIL, 2012), podemos também observar o distanciamento, nesses dez anos, das notas máximas com relação a nota média, revelando, assim, um aparente déficit na aprendizagem dessa área que contém as disciplinas de Língua Portuguesa, Literatura, Língua Estrangeira (Inglês ou Espanhol), Artes, Educação Física e Tecnologias da Informação e Comunicação como seus componentes curriculares. 
Gráfico 3. Notas mínimas, máximas e média de Matemática e suas Tecnologias

\section{MATEMÁTICA E SUAS TECNOLOGIAS}

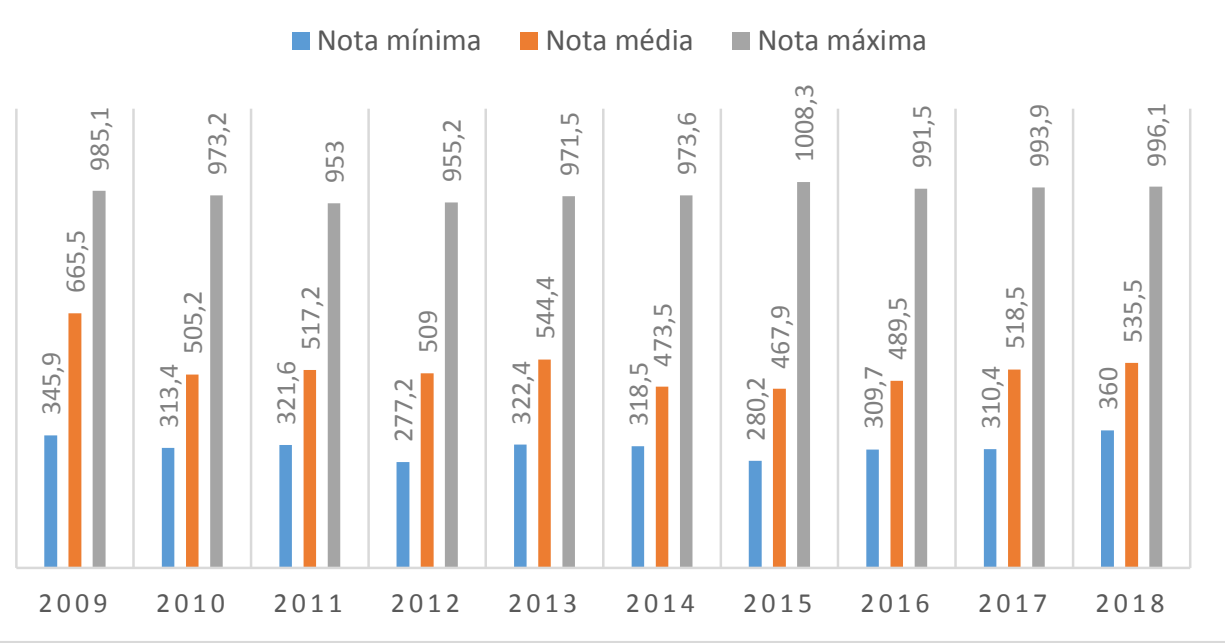

Fonte: Autoras (2019)

Com relação à Matemática e suas Tecnologias que envolvem conhecimentos numéricos, geométricos, de estatística e probabilidade, algébricos e algébricos/geométricos (BRASIL, 2012), é claramente a área de abrangência que apresenta o maior índice de dificuldade nas avaliações externas e que podem ser observadas neste gráfico uma explícita discrepância entre as notas mínimas, médias e máximas, isso é notório para os dez anos analisados. Com mais cautela chamamos a atenção para a menor nota média do período analisado que foi no ano de 2015, 467,9 , e a maior nota média foi em 2009 , com média 665,5 , ano também em que foi implantado o novo modelo de avaliação da prova. Vale ainda destacar que apesar de os alunos que realizaram a avaliação neste ano de 2015 obterem nota média em relação ao período mencionado, foi possível evidenciar que, neste mesmo ano, também apresentou a maior nota máxima, 1008,3 , resultado este obtido apenas por treze estudantes participantes do exame, isso aconteceu pela primeira vez na história do $\mathrm{ENEM}^{4}$, até então, a pontuação mais alta, havia sido em 2014, quando alguns candidatos pontuaram 973,6.

\footnotetext{
${ }^{4}$ Informação adicional retirada do site: 
Gráfico 4. Notas mínimas, máximas e média de Ciências Humanas e suas Tecnologias

\section{CIÊNCIAS HUMANAS E SUAS TECNOLOGIAS}

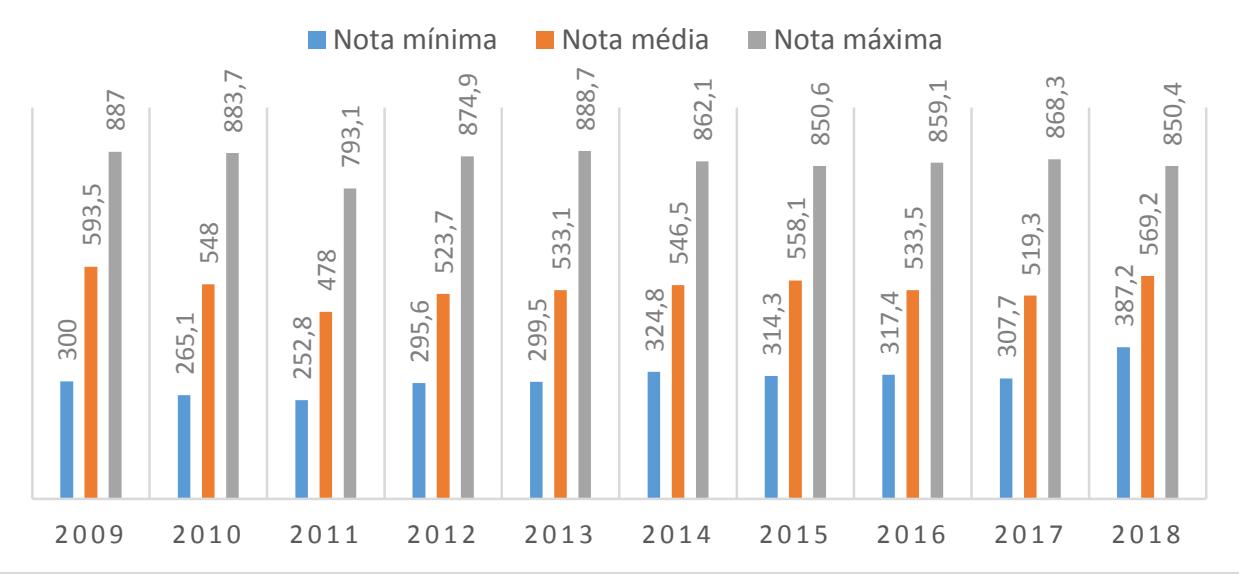

Fonte: Autoras (2019)

Nota: Elaborado a partir de dados de Inep (2019)

No que tange ao gráfico 4 apresentado acima, contempla-se os seguintes componentes curriculares, a saber: história, geografia, filosofia e sociologia em que são estudados a diversidade cultural, conflitos e vida em sociedade; formas de organização social, movimentos sociais, pensamento político e ação do Estado; características e transformações das estruturas produtiva; os domínios naturais e a relação homem/ambiente; e representação espacial (BRASIL, 2012) e indispensáveis para a formação crítica e reflexiva do alunado.
Observamos que 0 ano que obteve a menor nota média foi 2011 com 478 pontos, e a maior média foi em 2009, com pontuação de 593,5 . Visualizando de maneira geral, percebe-se que há uma considerável diferença entre a menor e a maior nota média no referenciado período, porém verifica-se uma proximidade entre as notas médias desta área, mas é notório destacar também o distanciamento, em cada ano, das notas mínimas, médias e máximas.

Gráfico 5. Notas mínimas, máximas e média de Ciências da natureza e suas Tecnologias

\section{CIÊNCIAS DA NATUREZA E SUAS TECNOLOGIAS}

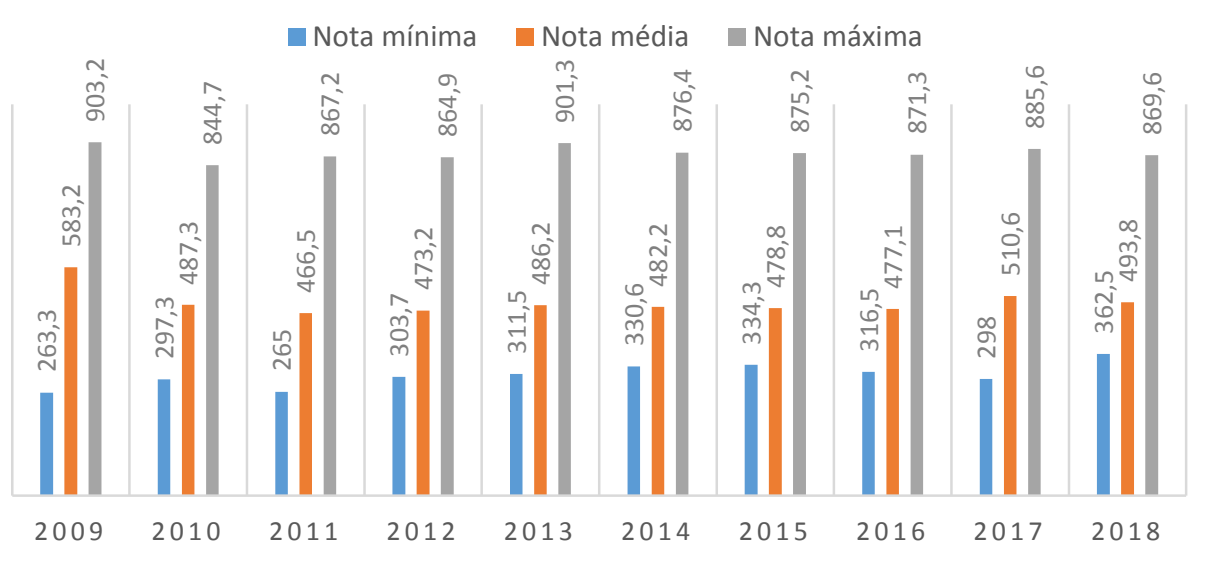

Fonte: Autoras (2019)

Nota: Elaborado a partir de dados de Inep (2019) 
O gráfico 5 nos mostra as notas aferidas do componente curricular de Química, Física e Biologia, que tem como objeto de conhecimento em química as transformações químicas, de energia e de equilíbrio, suas representações e dinâmica dessas transformações; água; materiais, suas propriedades e usos; compostos de carbono; relação da química com as tecnologias, a sociedade e o meio ambiente; e energias químicas no cotidiano. Em física o movimento; o equilíbrio e a descoberta de leis físicas; fenômenos elétricos, magnéticos e térmicos; mecânica e o funcionamento do universo; e oscilações, ondas, óptica e radiação. $E$, por último, em biologia moléculas, células e tecidos; hereditariedade e diversidade da vida; identidade dos seres vivos; ecologia e ciências ambientais; e origem, evolução e qualidade de vida. (BRASIL, 2012).

A leitura desse instrumento revela que a menor nota média encontra-se no ano de 2011 com nota de 466,5 , distanciando mais de cem pontos da pontuação média 583,2 alcançada no ano de 2009. Com efeito a essa sistematização, é importante salientar que ao longo desses dez anos analisados, esta área de conhecimento foi a que apresentou notas mais fragilizadas, comparadas com as demais, sendo assim, podese aferir uma certa dificuldade por parte dos alunos nesta área de conhecimento.

\section{CONCLUSÃO}

Ao retomar o objetivo geral proposto no trabalho, o qual buscou-se em expor e analisar o contexto das médias gerais do ENEM por área do conhecimento, através de dados coletados do site do INEP, ao longo de 10 anos (2009-2018), optamos por não adentrar na discussão qualitativa dos resultados do ENEM para não evadir o mesmo, mas, desde então, acreditamos que as avaliações externas revelam muito sobre a realidade da educação, porém desconsidera as especificidades do contexto escolar, o que se evidencia no campo amostral apresentado.

Destacamos mais uma vez que a análise dos dados em redação não foi estudada neste trabalho, pois ela não envolve o mesmo critério de avaliação que foram apresentados ao longo do texto.

Os dados apresentados neste trabalho demonstram que existe um notório distanciamento nas quatro áreas de conhecimento entre as notas mínimas, médias e máximas, revelando, por sua vez, a ineficiência (ou inaptidão) dos participantes no domínio dos conceitos cobrados na avaliação. Essa análise também nos permite destacar que a tão temida área de conhecimento "Matemática e suas Tecnologias" foi a que atingiu maiores notas máximas ao longo dos dez anos, chegando a ultrapassar os 1000 pontos, o que demonstra maior proficiência nos componentes curriculares avaliados. Prontamente, a área de conhecimento de Linguagens Códigos e suas Tecnologias, apresentou, de uma maneira geral, as notas mínimas mais baixas para o período estudado, evidenciando assim a fragilidade dessa área.

Numa ótica mais geral, os dados nos revelam um congelamento com relação as notas médias aritméticas em todas as áreas de conhecimento, o que nos provoca induzir um lineamento dos dados, isto é, pouco avanço na educação em termos quantitativos.

Dessa forma, apreendemos com essa análise, a desconexão do modelo de prova cobrado nas avaliações externas com relação aos componentes curriculares ensinados na sala de aula. Sugerimos com isso, um remodelamento colaborativo das estruturas curriculares de forma que essas estejam conectadas com a matriz de referência construída pelo INEP para o Exame Nacional do Ensino Médio.

\section{REFERÊNCIAS}

ARANHA, Maria Lucia de Almeida. História da educação e da pedagogia: geral e Brasil. 3. ed. São Paulo: Moderna, 2006.

BRASIL. Lei no 4.024, de 20 de dezembro de 1961. Fixa as Diretrizes e Bases da Educação Nacional. Diário Oficial da União, Brasília, DF, 27 dez. 1961. Disponível em: https://www2.camara.leg.br/legin/fed/lei/19601969/lei-4024-20-dezembro-1961-353722-

publicacaooriginal-1-pl.html. Acesso em: 18 abr. 2019.

BRASIL. Lei no 5.692, de 11 de agosto de 1971. Fixa Diretrizes e Bases para o ensino de 10 e 2응 graus, e dá outras providências. Diário Oficial da União, Brasília, DF, 12 ago. 1971. Disponível em: https://www2.camara.leg.br/legin/fed/lei/19701979/lei-5692-11-agosto-1971-357752-

publicacaooriginal-1-pl.html. Acesso em: 17 abr. 2019.

BRASIL. Lei no 9.394, de 20 de dezembro de 1996. Estabelece as diretrizes e bases da educação 
nacional. Diário Oficial da União, Brasília, DF, 23 dez.1996. Disponível em: http://www.planalto.gov.br/ccivil 03/leis/L9394. htm. Acesso em: 17 abr. 2019.

BRASIL. Lei no 13.415, de 16 de fevereiro de 2017. Altera as Leis $\mathrm{n}^{\text {os }}$ 9.394, de 20 de dezembro de 1996, que estabelece as diretrizes e bases da educação nacional, e 11.494, de 20 de junho 2007, que regulamenta o Fundo de Manutenção e Desenvolvimento da Educação Básica e de Valorização dos Profissionais da Educação, a Consolidação das Leis do Trabalho - CLT, aprovada pelo Decreto-Lei $\mathrm{n}^{\circ} \mathbf{5 . 4 5 2}$, de $1^{\circ}$ e maio de 1943, e o Decreto-Lei no 236, de 28 de fevereiro de 1967; revoga a Lei $\mathrm{n}^{\circ} 11.161$, de 5 de agosto de 2005; e institui a Política de Fomento à Implementação de Escolas de Ensino Médio em Tempo Integral. Diário Oficial da União, Brasília, DF, 12 fev. 2017. Disponível em: http://www.planalto.gov.br/ccivil 03/ Ato20152018/2017/Lei/L13415.htm. Acesso em: $10 \mathrm{abr}$. 2019.

BRASIL. Lei no 13.415, de 16 de fevereiro de 2017. Altera as Leis no 9.394, de 20 de dezembro de 1996, que estabelece as diretrizes e bases da educação nacional, e 11.494, de 20 de junho 2007, que regulamenta o Fundo de Manutenção e Desenvolvimento da Educação Básica e de Valorização dos Profissionais da Educação, a Consolidação das Leis do Trabalho - CLT, aprovada pelo Decreto-Lei no 5.452 , de 1 o de maio de 1943, e o Decreto-Lei no 236, de 28 de fevereiro de 1967; revoga a Lei no 11.161, de 5 de agosto de 2005; e institui a Política de Fomento à Implementação de Escolas de Ensino Médio em Tempo Integral. Diário Oficial da União, Brasília, DF, 17 fev. 2017. Disponível em: https://www2.camara.leg.br/legin/fed/lei/2017/l ei-13415-16-fevereiro-2017-784336-

publicacaooriginal-152003-pl.html. Acesso em: 29 abr. 2019.

BRASIL. Ministério da Educação e Cultura. Portaria no 438, de 28 de maio de 1988. Institui o Exame Nacional do Ensino Médio. Diário Oficial da União, DF, 01 jun. 1998. Disponível em: https://www.legisweb.com.br/legislacao/?id=181 748. Acesso em: 30 abr. 2019.

BRASIL. Ministério da Educação E Cultura. Instituto Nacional de Estudos e Pesquisas Educacionais Anísio Teixeira. Matriz de referência ENEM. 2012. Disponível em: http://portal.inep.gov.br/informacao-dapublicacao/Lasset publisher/6JYIsGMAMkW1/document/id/ 493832. Acesso em: 25 mai. 2019.

BRASIL. Ministério da Educação. Instituto Nacional de Estudos e Pesquisas Educacionais Anísio Teixeira. Relatório Pedagógico 2009-2010. $2013 . \quad$ Disponível em: http://download.inep.gov.br/educacao basica/e nem/downloads/2012/matriz referencia enem.p df. Acesso em: 04 mai. 2019.

BRZEINSKI, Iria et al. LDB Interpretada: diversos olhares se entrecruzam. São Paulo: Cortez, 2001.

CASTRO, Maria Helena Guimarães de. Enem: uma avaliação inovadora. INEP, 1999. Disponível em: http://inep.gov.br/artigo/-

Lasset publisher/B4AQV9zFY7Bv/content/enemuma-avaliacao-inovadora/21206. Acesso em: 19 maio 2019.

CRESPO, Antônio Arnot. Estatística Fácil. 19. ed. São Paulo: Saraiva, 2009.

MARTINS, Gilberto de Andrade; DOMINGUES, Osmar. Estatística geral e aplicada. 6. ed. São Paulo: Atlas, 2017.

QEDU, 2019. Disponível em: https://www.qedu.org.br/. Acesso em: 10 maio 2019.

RICHARDSON, Roberto Jarry et al. Pesquisa Social: métodos e técnicas. 3 ed. São Paulo: Atlas, 2012.

ROMANELLI, Otaíza de Oliveira. História da Educação no Brasil: (1930/1973). 36. ed. Petrópolis, RJ: Vozes, 2010.

SAKALAUSKAS, Silvia Renata.; TREVISAN, André Luis. Enem: rompendo paradigmas para a conclusão do Ensino Médio. Revista Debates em Educação, v. 9, n.19, p. 01-18, set/dez 2017. Disponível em: http://www.seer.ufal.br/index.php/debateseduc acao/article/view/2811. Acesso em: 08 abr. 2019. https://doi.org/10.28998/2175$\underline{6600.2017 v 9 n 19 p 01}$ 